\title{
Long-term effects of a protein-enriched diet on blood pressure in older women
}

\author{
Jonathan M. Hodgson ${ }^{1 *} \dagger$, Kun Zhu ${ }^{2,3} \dagger$, Joshua R. Lewis ${ }^{2,3}$, Deborah Kerr $^{4}$, Xingqiong Meng ${ }^{4}$, \\ Vicky Solah ${ }^{4}$, Amanda Devine ${ }^{5}$, Colin W. Binns ${ }^{4}$, Richard J. Woodman ${ }^{6}$ and Richard L. Prince ${ }^{2,3}$ \\ ${ }^{1}$ Royal Perth Hospital Unit, School of Medicine and Pharmacology, University of Western Australia, GPO Box X2213, Perth, \\ Western Australia 6847, Australia \\ ${ }^{2}$ Sir Charles Gairdner Hospital Unit, School of Medicine and Pharmacology, University of Western Australia, Western \\ Australia, Australia \\ ${ }^{3}$ Department of Endocrinology and Diabetes, Sir Charles Gairdner Hospital, Western Australia, Australia \\ ${ }^{4}$ Curtin Health Innovation Research Institute and the School of Public Health, Curtin University, Western Australia, Australia \\ ${ }^{5}$ School of Exercise, Biomedical and Health Sciences, Edith Cowan University, Perth, Western Australia, Australia \\ ${ }^{6}$ Discipline of General Practice, Flinders University, Adelaide, South Australia, Australia
}

(Received 4 March 2011 - Revised 21 June 2011 - Accepted 26 July 2011)

\section{Abstract}

Short-term randomised, controlled trials have found that dietary protein relative to carbohydrate can reduce blood pressure. Our objective was to investigate the effects on blood pressure of an increase in protein intake from whey over 2 years in women aged over 70 years. From the general population, 219 women aged between 70 and 80 years were recruited to a 2-year randomised, double-blind, placebo-controlled parallel-design trial: 181 women completed the trial to the end of year 2. Participants were randomly assigned to consume a daily whey protein-based beverage (protein) or an energy-matched low-protein high-carbohydrate beverage (control). Blood pressure measurements were performed at baseline, year 1 and year 2. For protein relative to control, the estimated mean net differences in protein and carbohydrate intakes were $18(95 \% \mathrm{CI} 13,23)$ and $-22(95 \% \mathrm{CI}-9,-35) \mathrm{g} / \mathrm{d}$ at year 1 , and $22(95 \% \mathrm{CI}$ $17,28)$ and $-18(95 \% \mathrm{CI}-6,-31) \mathrm{g} / \mathrm{d}$ at year 2 . Intention-to-treat analysis found no overall differences between groups in blood pressure $(P>0.5)$. Net differences in systolic and diastolic blood pressure were $-2.3(95 \% \mathrm{CI}-5.3,0.7)$ and $-1.5(95 \% \mathrm{CI}-3.6,0 \cdot 6) \mathrm{mmHg}$ at year 1 , and $1.6(95 \% \mathrm{CI}-1.5,4.7)$ and $0.3(95 \% \mathrm{CI}-1.9,2.4) \mathrm{mmHg}$ at year 2 . Similar differences in systolic and diastolic blood pressure at years 1 and 2 were observed with per-protocol analysis. Therefore, the present study did not provide evidence that a higher whey protein intake in older women can have prolonged effects on blood pressure.

Key words: Protein: Blood pressure: Carbohydrate

Hypertension is the leading risk factor worldwide for total and CVD mortality ${ }^{(1)}$. Changes to diet and lifestyle within populations have been advocated as the major means of combating hypertension. Several dietary and lifestyle modifications have proven beneficial for reducing blood pressure ${ }^{(2)}$, but the benefits of increasing total and/or animal-derived protein intake remain contentious ${ }^{(3,4)}$.

The role of protein intake in determining blood pressure has been investigated in population studies and randomised controlled trials. Approximately two-thirds of more than twenty-five cross-sectional population studies report an inverse relationship between estimated protein intake and blood pressure $^{(4-6)}$. This inverse relationship appears to be more robust for plant protein ${ }^{(3,4,7)}$. However, several cross-sectional studies, primarily in Asian populations, find an inverse association between animal protein intake specifically and blood pressure $^{(4)}$. The relationship for both animal protein and plant protein may be influenced by dietary and lifestyle factors associated with their intake, and with level of blood pressure.

Partial replacement of carbohydrate in the diet with protein can lower blood pressure. A lower blood pressure with protein, derived from plant, mixed, or animal sources, compared with carbohydrate has been demonstrated in several randomised controlled trials ${ }^{(8-12)}$. Although results of cross-sectional population studies suggest that plant protein may be superior to animal protein, results of several trials indicate little difference between animal and plant proteins in their effects on blood pressure ${ }^{(13-16)}$. These studies suggest a beneficial

*Corresponding author: Dr J. M. Hodgson, fax +61 89224 0246, email jonathan.hodgson@uwa.edu.au

† Joint first authors. 
effect on blood pressure of protein relative to carbohydrate, and that type of protein may not be an important determinant of effects.

However, the translation of the results of these studies into population advice to manage blood pressure remains contentious. In many populations, advice to increase protein intake is likely to result primarily in increases in the intake of animal protein. There are few trials that have investigated the effects of animal protein specifically, relative to carbohydrate $e^{(11)}$. In addition, there are few studies that have investigated the longer-term effects of higher protein intakes on blood pressure. Data from prospective studies ${ }^{(17-19)}$ and longerterm randomised controlled trials ${ }^{(12,20)}$, which may provide a better indication of longer-term effects, remain limited. Furthermore, there is some indication that the benefits of protein on blood pressure may be larger in older individuals. Therefore, the objective of the present trial was to investigate the long-term effects on blood pressure, over 2 years, of an increase in protein intake from whey in elderly women.

\section{Methods}

\section{Participants}

Study participants were recruited from the general population between April and September 2007. A population-based approach was used in which a random selection of women ( $n$ 6065) aged 70-80 years on the electoral roll in Western Australia received a letter inviting them to join the study. Over $98 \%$ of women of this age are on the Western Australian electoral roll. Of the 829 women who responded to the letter, 256 attended clinic screening and 219 women who met the inclusion criteria joined the study. The exclusion criteria were: participation in another clinical trial during the previous 12 weeks; $\mathrm{BMI}>35 \mathrm{~kg} / \mathrm{m}^{2}$; clinical diagnosis of diabetes; history of gastrointestinal disease or disorder; clinical hepatic or renal insufficiency; high protein intake as assessed by FFQ (equivalent to protein intake more than $1.5 \mathrm{~g} / \mathrm{kg}$ body weight per $\mathrm{d}$ ); lactose intolerance or unwillingness to consume milk products; previous osteoporotic fracture or metabolic bone disease apart from osteoporosis; currently or within last year, taking medication for osteoporosis apart from calcium or vitamin D; recent use of oral steroids; total hip bone density more than $2 \mathrm{SD}$ below the mean for their age; cognitive impairment (Mini Mental State Score $<24$ ); and participants who, in the opinion of the investigator, were not likely to complete the study for any reason. The study population, women over 70 years, was chosen because they are at increased risk of both hypertension and CVD; effects of dietary factors to influence blood pressure in this population could have a significant impact on risk of heart disease and stroke; and the effects of dietary protein on blood pressure have yet to be investigated in older individuals.

All procedures followed were in accordance with institutional guidelines. The present study was conducted according to the guidelines laid down in the Declaration of Helsinki and all procedures involving human subjects were approved by the Sir Charles Gairdner Hospital Human Research Ethics
Committee. Written informed consent was obtained from all subjects. The study was registered with the Australian New Zealand Clinical Trials Registry (Registration no. ACTRN012607000163404).

\section{Design, randomisation and blinding}

The study design was a 2-year randomised, double-blind, placebo-controlled trial. Eligible participants were randomised to one of two treatment groups: protein or placebo (control). Group allocation was achieved using a computer-generated randomisation sequence with a block size of 10 to assign participants to protein or control in a ratio of $1: 1$. The randomisation code was generated by one of the investigators (C. W. B.), who did not have direct contact with the participants, and was kept at the School of Public Health, Curtin University. Staff of Curtin University dispensed the powder to participants in tins labelled only with subjects' name and study ID, which were delivered by courier to the participants every 3 months. The study participants and researchers responsible for assessment of outcome measures remained blinded to the assignment individuals' group. The code break was applied after the outcome data had been entered into electronic files.

\section{Supplements}

Participants consumed $250 \mathrm{ml} / \mathrm{d}$ of their assigned supplement (beverage). The $250 \mathrm{ml}$ high-protein beverage provided $30 \mathrm{~g}$ of protein, $600 \mathrm{mg}$ of calcium and $3 \cdot 2 \mathrm{~kJ} / \mathrm{ml}(810 \mathrm{~kJ})$. The $250 \mathrm{ml}$ low-protein (control) beverage provided $2 \cdot 1 \mathrm{~g}$ of protein, $600 \mathrm{mg}$ of calcium and $3.3 \mathrm{~kJ} / \mathrm{ml}(820 \mathrm{~kJ})$. The base product for both beverages was skimmed milk. The high-protein product had whey protein isolate (Alacen 894; Fonterra Brands Limited, Balcatta, Western Australia, Australia) added, while carbohydrate (maltodextrin) was used in the low-protein (control) beverage to match for the energy. The nutrient composition of the two supplements is presented in Table 1. Alginate natural flavouring and natural emulsifying agents were used to provide a similar texture and flavour to the drinks. The supplements were provided to participants as a powder which was reconstituted to $250 \mathrm{ml}$ with cold water before consumption. To aid in adherence, the participants were provided with a diary in which they marked the consumption of the product. To validate this consumption, a count was made of empty tins and those that contained unused powder returned at the clinic visit at the end of year 1 and year 2 .

Table 1. Nutrient composition of the supplements (per $250 \mathrm{ml}$ daily intake)

\begin{tabular}{lcc}
\hline & Control drink & Protein drink \\
\hline Energy (kJ) & 820 & 810 \\
Protein (g) & 2 & 30 \\
Fat (g) & 2 & 2 \\
Carbohydrate (g) & 42 & 13 \\
Ca (mg) & 600 & 603 \\
$\mathrm{Na}(\mathrm{mg})$ & 33 & 48 \\
\hline
\end{tabular}




\section{Anthropometry and physical activity assessment}

Anthropometric measurements were performed with subjects in light clothes and without shoes. Standing height was measured using a wall-mounted stadiometer (Veeder-Root, Elizabethtown, NC, USA) to the nearest $0 \cdot 1 \mathrm{~cm}$. Body weight was measured using an electronic scale (August Sauter GmbH, D-7470 Albstadt 1 Ebingen, Germany) to the nearest $0 \cdot 1 \mathrm{~kg}$. Physical activity level was assessed by the International Physical Activity Questionnaire short form (www.ipaq.ki.se).

\section{Dietary intakes}

Dietary intake was assessed by a 3 -d weighed food record (2 week-days, one weekend day). Participants were asked to record everything they ate and drank for three consecutive days, using electronic food scales provided and household measures. They watched a training video on how to complete their food record before undertaking the food record. When the food record was returned 1 week later, the participant was interviewed to clarify the types and amount of food or beverages recorded. The food record was analysed using the AUSNUT99 database (Foodworks Professional edition version 3.02) by nutritionists trained in dietary assessment.

\section{Blood pressure}

Blood pressure was assessed using an automated sphygmomanometer (Critikon Dinamap 8100; Non-Invasive Blood Pressure Monitor, GE Healthcare, Rydalmere, New South Wales, Australia). Participants were seated for $5 \mathrm{~min}$, relaxed and not moving or speaking in a quiet temperature-controlled $\left(23-24^{\circ} \mathrm{C}\right)$ room. The left arm was supported at the level of the heart and it was ensured that the arm was not constricted by tight clothing. The measurements were repeated three times at 1 min intervals and the average of the three measurements was entered into the database. Participants were instructed not to take any medication in the morning before blood pressure was measured.

\section{Biochemistry}

Venous blood samples were collected following a $12 \mathrm{~h}$ fast from the antecubital vein of the forearm. Blood was collected into BD Vacutainer ${ }^{\circledR}$ (BD Australian and New Zealand, North Ryde, NSW, Australia) heparin or SST tubes. A $24 \mathrm{~h}$ urine collection was performed on the third day of the food recording period in a 5 litre plastic collection bottle which contained $20 \mathrm{ml}$ of $1 \mathrm{M}-\mathrm{HCl}$. Participants were instructed to commence on waking in the morning immediately following voiding their bladder. All urine was then collected for $24 \mathrm{~h}$, with the final sample in the morning on waking the next day. All biochemical analyses were performed in the PathWest Laboratory at the Royal Perth Hospital, Perth, Western Australia. Analyses of glucose were performed on plasma samples within $4 \mathrm{~h}$ of collection, which were centrifuged within $30 \mathrm{~min}$ after the blood was taken and transported to the laboratory on ice. Analyses of lipids and insulin were performed on sera stored at $-80^{\circ} \mathrm{C}$, in a single batch to reduce variability. Analyses of urinary sodium, potassium and creatinine excretion were performed on urine stored at $-20^{\circ} \mathrm{C}$, in a single batch.

Serum total cholesterol, HDL-cholesterol and TAG concentrations were analysed with a fully automated analyser (Architect c16000; Abbott Laboratories, Abbott Park, IL, USA). The assay CV were less than $0.6 \%$ for total cholesterol, $2.2 \%$ for TAG and $2.3 \%$ for HDL-cholesterol. Serum LDLcholesterol was calculated using the Friedewald equation ${ }^{(21)}$. Serum glucose was measured using a hexokinase/G-6-PDH method (Abbott Laboratories), using a fully automated analyser (Architect c16000). The assay CV was less than $1 \%$. Serum insulin was analysed by immunoassay (Abbott Laboratories) using a fully automated analyser (Architect c16000), with an assay CV of less than $1.5 \%$. The homeostasis model assessment score was calculated with the following formula ${ }^{(22)}$ (serum glucose $(\mathrm{mmol} / \mathrm{l}) \times \operatorname{serum}$ insulin $(\mu \mathrm{U} / \mathrm{ml}) / 22.5)$, to estimate changes in insulin sensitivity. Urinary sodium and potassium concentrations were analysed using an ion-selective electrode with an automated analyser (Roche Hitachi 917; Castle Hill, New South Wales, Australia). The CV of the sodium and potassium assays were $<2 \%$.

\section{Adverse events}

Using a previously validated method ${ }^{(23)}$, participants were asked to fill out an adverse-event diary in which each contact with a physician was recorded. At 6-month intervals, the diary was returned to the study centre at clinic visit or by mail. The adverse events were coded using the International Classification of Primary Care (ICPC2 Plus) system database of disease coding, a validated method of event recording developed for use in general practice ${ }^{(24)}$.

\section{Statistical analysis}

Statistical analyses were performed using SPSS 17.0 software (SPSS, Inc., Chicago, IL, USA) or SAS 9.2 software (SAS Institute, Cary, NC, USA). Power calculations were performed before the commencement of the study. For at least $80 \%$ power and $5 \%$ level of significance, a sample size of 100 participants in each group was required to detect a difference of $3 \mathrm{mmHg}$ in systolic blood pressure. We assumed a standard deviation of the difference of $10 \mathrm{mmHg}$ based on our previous studies, two post-baseline measurements (at year 1 and year 2) and a correlation between measures of 0.65 . The primary analysis was intention-to-treat. The intention-to-treat population was defined as all participants randomised to the study, for which there were baseline measurements. In this analysis, there was no replacement of missing data. Therefore, the number of data points included in the analysis depended on the number of participants and measurements at each time point for the parameter of interest. Per-protocol analysis was also performed. The per-protocol analysis included participants who: completed the 2-year trial; consumed at least $70 \%$ of the supplements provided during both year 1 and year 2; and did not alter their antihypertensive medication 


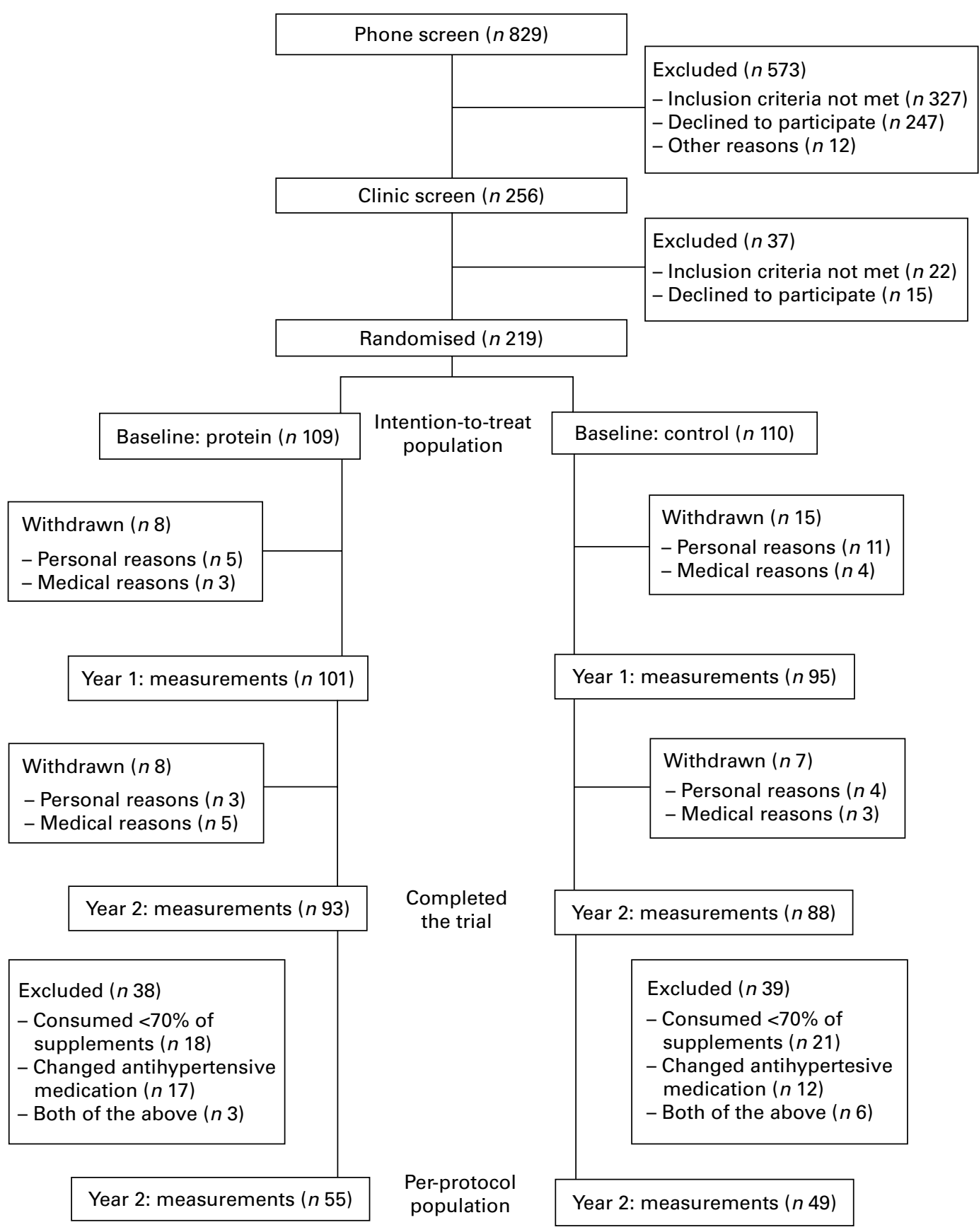

Fig. 1. Flow chart of participants.

during the trial. For descriptive data, results are presented as means and standard deviations except for insulin and TAG which were log-transformed and are reported as geometric mean and 95\% CI. The baseline-adjusted between-group differences are presented as mean (95\% CI), with $P<0.05$ in a two-tailed test set as the level of significance. At baseline, characteristics of participants in the two groups, including nutrient intakes, were compared using the independentsamples $t$ test and the $\chi^{2}$ test for categorical variables. At year 1 and year 2, differences between groups in nutrient intakes were analysed using univariate general linear models with adjustment for baseline values. The PROC MIXED procedure in SAS was used to assess baseline-adjusted between-group differences in blood pressure during the 2-year intervention, and specifically at year 1 and year 2 . Models used included fixed effects of baseline value, treatment group, time and a treatment group $\times$ time interaction term. Between-group differences were also adjusted for potential confounding factors, including age, body weight, alcohol intake, and urinary sodium and potassium excretion, which were included as covariates in the models. Separate sub-group analyses of blood pressure differences in women with systolic blood pressure greater than $140 \mathrm{mmHg}$ at baseline were also performed using mixed-effects models. 


\section{Results}

\section{Participants and baseline characteristics}

A total of 219 women (110 in the control group and 109 in the protein group) aged 70-80 years were randomised and commenced the study. Of these, 196 (ninety-five control, 101 protein; 89.5\%) women had measurements taken at the end of year 1, and 181 women (eighty-eight control, ninety-three protein; $82.6 \%$ ) had measurements taken at the end of year 2 (Fig. 1). The two groups were well matched at baseline, and there were no significant differences between groups in baseline characteristics (Table 2). The groups were also well matched according to use of specific classes of antihypertensive medications. In the control group, thirteen were taking an angiotensin-converting enzyme inhibitor; eighteen, an angiotensin II receptor blocker; nine, a calcium channel entry blocker; eight, a $\beta$-blocker; and six, a diuretic. In the protein group, nine were taking an angiotensin-converting enzyme inhibitor; eighteen, an angiotensin II receptor blocker; nine, a calcium channel entry blocker; nine, a $\beta$-blocker; and eleven, a diuretic. There were no significant differences between groups in the use of specific classes of antihypertensive medications.

Among the 196 participants who completed the trial to the end of year 1, compliance with the assigned supplement was 78 (SD 29) \% for protein and 72 (SD 31) \% for control. Among the 181 participants who completed the trial to the end of year 2, compliance with the assigned supplement was 88 (SD 25) \% for protein and 81 (SD 25) \% for control. The baseline characteristics of the participants who withdrew from the trial were not significantly different from those who completed the trial. There were no reported adverse effects from consuming either the control or the protein beverages during the 2-year study.

\section{Energy, nutrient intake and physical activity}

Body weight, energy and nutrient intakes and physical activity levels were well matched between groups at baseline (Table 3). Estimated energy intakes at baseline, year 1 and year 2 were not significantly different between groups. For protein relative to control, the estimated mean (95\% CI) net differences in protein and carbohydrate intakes were 18 $(13,23)$ and $-22(-9,-35) \mathrm{g} / \mathrm{d}$ at year 1 , and $22(17,28)$ and $-18(-6,-31) \mathrm{g} / \mathrm{d}$ at year 2 . At year 1 , the sodium and potassium excretion was not different between groups, but at year 2, potassium excretion was higher for protein compared to control. There was a similar non-significant trend for sodium such that the sodium:potassium ratio was not different between groups (Table 3).

\section{Blood pressure}

The mean systolic and diastolic blood pressures were well matched between the groups at baseline (Table 2). The mean baseline-adjusted blood pressures in each group during the 2-year intervention and specifically at year 1 and year 2 are presented in Table 4 . There were no significant differences in systolic or diastolic blood pressures between groups at year 1 or year 2 .

A per-protocol analysis included 104 women (Fig. 1) who completed the 2-year trial, did not alter their antihypertensive medication, and consumed at least $70 \%$ of the supplements during the trial. For protein relative to control, the overall differences in systolic and diastolic blood pressures were 0.6 $(-2 \cdot 1, \quad 3 \cdot 2) \mathrm{mmHg}, \quad P=0.68$ and $0 \cdot 1 \quad(-1 \cdot 9, \quad 2 \cdot 2) \mathrm{mmHg}$, $P=0 \cdot 90$, respectively. Net differences in systolic and diastolic blood pressures were $-2.9(-7 \cdot 0,1.3) \mathrm{mmHg}, P=0 \cdot 18$ and $-1.8(-4.8,1.3) \mathrm{mmHg}, P=0.26$ at year 1 , and $3.3(-1.0$, 7.5) $\mathrm{mmHg}, P=0.12$ and $1.6(-2.5,3.0) \mathrm{mmHg}, P=0.85$ at year 2. Adjustment for age, body weight, alcohol intake, and urinary sodium and potassium excretion, did not alter interpretation of the results.

\section{Discussion}

We aimed to investigate the long-term effects on blood pressure of a diet higher in protein. A total of 219 women aged 70-80 years were recruited to this trial. In the intention-to-treat and per-protocol analyses, there were no significant differences observed in either systolic or diastolic blood pressure between groups.

Hypertension is the leading risk factor for total and CVD mortality and is responsible for $13 \%$ of deaths globally ${ }^{(25)}$. It currently affects more than one-quarter of the world's population $^{(26)}$, and often more than half of all men and women aged over 70 years ${ }^{(27,28)}$. In the present study, the prevalence of hypertension, defined as those receiving antihypertensive medication or with systolic blood pressure at baseline greater than $140 \mathrm{mmHg}$, was $70 \%$. The worldwide prevalence of

Table 2. Characteristics of the women in the control and protein groups at baseline*

(Mean values and standard deviations or geometric means and $95 \%$ confidence intervals)

\begin{tabular}{|c|c|c|c|c|}
\hline & \multicolumn{2}{|c|}{ Control (n 110) } & \multicolumn{2}{|c|}{ Protein $(n 109)$} \\
\hline & Mean & SD & Mean & SD \\
\hline Age (years) & $74 \cdot 3$ & $2 \cdot 6$ & $74 \cdot 3$ & $2 \cdot 7$ \\
\hline Height (m) & 1.60 & 0.06 & 1.60 & 0.06 \\
\hline Body weight (kg) & $69 \cdot 7$ & 11.5 & $67 \cdot 4$ & $11 \cdot 1$ \\
\hline BMI $\left(\mathrm{kg} / \mathrm{m}^{2}\right)$ & $27 \cdot 2$ & 3.9 & $26 \cdot 3$ & 3.8 \\
\hline Antihypertensive medication (\%) & 52 & & 50 & 50 \\
\hline Systolic pressure $(\mathrm{mmHg})$ & $142 \cdot 9$ & $15 \cdot 6$ & $142 \cdot 9$ & 17.5 \\
\hline Diastolic pressure $(\mathrm{mmHg})$ & $70 \cdot 1$ & $10 \cdot 8$ & $69 \cdot 6$ & 11.9 \\
\hline Total cholesterol $(\mathrm{mmol} / \mathrm{l})$ & $5 \cdot 66$ & 0.97 & $5 \cdot 73$ & $1 \cdot 12$ \\
\hline LDL-cholesterol (mmol/l) & $3 \cdot 28$ & 0.86 & 3.35 & 1.01 \\
\hline HDL-cholesterol (mmol/l) & 1.74 & 0.40 & 1.79 & 0.40 \\
\hline \multicolumn{5}{|l|}{ TAG $(\mathrm{mmol} / \mathrm{l})$} \\
\hline Geometric mean & \multicolumn{2}{|c|}{1.31} & \multicolumn{2}{|c|}{$1 \cdot 18$} \\
\hline $95 \% \mathrm{Cl}$ & \multicolumn{2}{|c|}{$1 \cdot 21,1.40$} & \multicolumn{2}{|c|}{$1 \cdot 09,1 \cdot 28$} \\
\hline Glucose $(\mathrm{mmol} / \mathrm{l})$ & $5 \cdot 32$ & 0.50 & $5 \cdot 28$ & 0.49 \\
\hline \multicolumn{5}{|l|}{ Insulin (mU/l) } \\
\hline Geometric mean & \multirow{2}{*}{\multicolumn{2}{|c|}{$\begin{array}{c}8.05 \\
7.41,8.76\end{array}$}} & \multirow{2}{*}{\multicolumn{2}{|c|}{$\begin{array}{c}7 \cdot 18 \\
6 \cdot 60,7 \cdot 80\end{array}$}} \\
\hline $95 \% \mathrm{Cl}$ & & & & \\
\hline HOMA-IR (units) & $2 \cdot 1$ & 0.9 & 1.9 & 0.9 \\
\hline
\end{tabular}

HOMA-IR, homeostasis model assessment-insulin resistance.

* Between-group differences analysed using the independent-samples $t$ test and the $\chi^{2}$ test for categorical variables. There were no significant differences between groups for any of the variables reported. 
Table 3. Mean body weight, energy and nutrient intakes and physical activity levels of the women in the control and protein groups at baseline, year 1 and year 2 (Mean values and standard deviations)

\begin{tabular}{|c|c|c|c|c|c|c|c|c|c|c|c|c|}
\hline & \multicolumn{6}{|c|}{ Control } & \multicolumn{6}{|c|}{ Protein } \\
\hline & \multicolumn{2}{|c|}{ Baseline ( $n$ 110) } & \multicolumn{2}{|c|}{ Year 1 ( $n$ 92) } & \multicolumn{2}{|c|}{ Year 2 ( $n$ 87) } & \multicolumn{2}{|c|}{ Baseline ( $n$ 108) } & \multicolumn{2}{|c|}{ Year 1 ( $n$ 96) } & \multicolumn{2}{|c|}{ Year 2 ( $n$ 93) } \\
\hline & Mean & SD & Mean & SD & Mean & SD & Mean & SD & Mean & SD & Mean & SD \\
\hline Body weight (kg) & 69.7 & 11.5 & $70 \cdot 6$ & $11 \cdot 7$ & $69 \cdot 7$ & 11.4 & $67 \cdot 4$ & $11 \cdot 1$ & $67 \cdot 4$ & $11 \cdot 7$ & 67.5 & 11.4 \\
\hline Energy $(\mathrm{kJ} / \mathrm{d})$ & 7058 & 1422 & $7595^{\star}$ & 1717 & 7184 & 1435 & 7075 & 1517 & 7381 & 1904 & 7317 & 1717 \\
\hline \multicolumn{13}{|l|}{ Total fat } \\
\hline $\mathrm{g} / \mathrm{d}$ & 61 & 20 & $66^{*}$ & 23 & 60 & 17 & 63 & 19 & 64 & 24 & 62 & 20 \\
\hline$\%$ of energy & 32 & 6 & 32 & 6 & $31^{*}$ & 5 & 33 & 5 & $32^{*}$ & 6 & $31 \dagger$ & 6 \\
\hline \multicolumn{13}{|l|}{ Protein } \\
\hline $\mathrm{g} / \mathrm{d}$ & 75 & 16 & 75 & 17 & 73 & 17 & 75 & 18 & 93†† & 19 & $96+\ddagger$ & 20 \\
\hline $\mathrm{g} / \mathrm{kg}$ body weight per $\mathrm{d}$ & $1 \cdot 1$ & 0.3 & 1.1 & 0.3 & $1 \cdot 1$ & 0.4 & $1 \cdot 1$ & 0.3 & $1.4 \dagger \ddagger$ & 0.4 & $1.4 \dagger \ddagger$ & 0.4 \\
\hline$\%$ of energy & 19 & 3 & $17 \dagger$ & 3 & $18^{*}$ & 3 & 19 & 4 & 22†‡ & 4 & $23 \dagger \ddagger$ & 5 \\
\hline \multicolumn{13}{|l|}{ Carbohydrate intake } \\
\hline$g / d$ & 189 & 42 & $211 \dagger$ & 50 & $203^{*}$ & 48 & 184 & 44 & $187 \ddagger$ & 53 & $183 \S$ & 52 \\
\hline$\%$ of energy & 46 & 7 & 46 & 6 & 46 & 6 & 45 & 6 & $41 \dagger \ddagger$ & 6 & $41 \dagger \ddagger$ & 6 \\
\hline Fibre $(g / d)$ & 22 & 7 & $20 \ddagger$ & $6 \ddagger$ & $20^{*}$ & 6 & 23 & 7 & $19 \dagger$ & 7 & $21^{*}$ & 7 \\
\hline \multicolumn{13}{|l|}{ Alcohol } \\
\hline$g / d$ & $6 \cdot 8$ & $10 \cdot 2$ & $6 \cdot 3$ & $9 \cdot 2$ & $5 \cdot 7$ & 7.9 & $7 \cdot 1$ & $10 \cdot 7$ & $5 \cdot 6$ & $10 \cdot 3$ & $6 \cdot 7$ & $9 \cdot 7$ \\
\hline$\%$ of energy & $2 \cdot 7$ & $4 \cdot 0$ & $2 \cdot 4$ & 3.5 & $2 \cdot 2$ & $3 \cdot 1$ & $2 \cdot 8$ & $4 \cdot 2$ & 1.9 & 3.5 & $2 \cdot 6$ & 3.9 \\
\hline Na excretion $(\mathrm{mmol} / \mathrm{d})$ & 100 & 43 & 109 & 47 & 103 & 37 & 111 & 53 & 116 & 47 & 117 & 42 \\
\hline K excretion (mmol/d) & 57 & 21 & 62 & 22 & 59 & 21 & 62 & 23 & 65 & 19 & $69^{*} \S$ & 20 \\
\hline Ca intake (mg/d) & 1021 & 439 & $1414 \dagger$ & 453 & $1377 \dagger$ & 411 & 978 & 376 & $1347 \dagger$ & 379 & $1364 \dagger$ & 413 \\
\hline Activity (Met-min/week) & 443 & 386 & 441 & 394 & 424 & 406 & 374 & 363 & 429 & 389 & 385 & 356 \\
\hline
\end{tabular}

* Mean values were significantly different from that at baseline $(P<0.01)$

¥ Mean values were significantly different from that of the control group at the same time point $(P<0.001)$.

$\S$ Mean values were significantly different from that of the control group at the same time point $(P<0.01)$. 
Table 4. Mean baseline-adjusted systolic and diastolic blood pressures of the women in the protein and control groups during the 2-year intervention and specifically at year 1 and year 2 of the trial ${ }^{*}$

(Mean values and $95 \%$ confidence intervals)

\begin{tabular}{|c|c|c|c|c|c|c|c|}
\hline & \multicolumn{2}{|c|}{ Control } & \multicolumn{2}{|c|}{ Protein } & \multicolumn{2}{|c|}{ Difference } & \multirow[b]{2}{*}{$P \dagger$} \\
\hline & Mean & $95 \% \mathrm{Cl}$ & Mean & $95 \% \mathrm{Cl}$ & Mean & $95 \% \mathrm{Cl}$ & \\
\hline \multicolumn{8}{|l|}{ Overall } \\
\hline Systolic blood pressure $(\mathrm{mmHg})$ & $134 \cdot 2$ & $132 \cdot 1,136 \cdot 3$ & 133.9 & $131 \cdot 9,136 \cdot 0$ & -0.3 & $-3 \cdot 2,2 \cdot 7$ & 0.86 \\
\hline Diastolic blood pressure (mmHg) & 67.4 & $65.9,68.9$ & $66 \cdot 7$ & $65 \cdot 2,68 \cdot 1$ & -0.7 & $-2 \cdot 8,1 \cdot 4$ & 0.50 \\
\hline \multicolumn{8}{|l|}{ Year 1} \\
\hline Systolic blood pressure $(\mathrm{mmHg})$ & $135 \cdot 7$ & $133 \cdot 5,137 \cdot 8$ & 133.4 & $131 \cdot 3,135 \cdot 5$ & $-2 \cdot 3$ & $-5 \cdot 3,0.7$ & 0.14 \\
\hline Diastolic blood pressure $(\mathrm{mmHg})$ & $67 \cdot 1$ & $65 \cdot 6,68 \cdot 6$ & 65.5 & $64 \cdot 1,67 \cdot 0$ & -1.5 & $-3 \cdot 6,0.6$ & 0.15 \\
\hline \multicolumn{8}{|l|}{ Year 2} \\
\hline Systolic blood pressure $(\mathrm{mmHg})$ & $133 \cdot 0$ & $130 \cdot 7,135 \cdot 2$ & 134.6 & $132 \cdot 4,136 \cdot 8$ & 1.6 & $-1.5,4.7$ & 0.30 \\
\hline Diastolic blood pressure $(\mathrm{mmHg})$ & $67 \cdot 6$ & $66 \cdot 0,69 \cdot 2$ & $67 \cdot 8$ & $66 \cdot 3,69 \cdot 4$ & 0.3 & $-1 \cdot 9,2 \cdot 4$ & 0.82 \\
\hline
\end{tabular}

* Intention-to-treat population.

$\dagger P$-value is for baseline-adjusted between-group differences analysed using mixed-effects models.

$\ddagger$ Overall mean baseline-adjusted blood pressures and baseline-adjusted between-group differences during the 2-year trial.

hypertension is projected to rise considerably due to an increase in prevalence in developing countries and an increase in life expectancy in many of the populations ${ }^{(26)}$. The impact on blood pressure of advice to alter protein intake in this population is unclear.

Lower blood pressure with higher protein intake is a consistent finding in population studies ${ }^{(3,4)}$. In addition, a reduction in blood pressure with protein compared with carbohydrate is a consistent finding in previous short-term randomised controlled trials ${ }^{(8-11)}$. Although the population data indicate the potential for greater benefits of plant protein ${ }^{(4,7)}$, results of intervention studies indicate little difference between plant and animal proteins in their effects on blood pressure $^{(13-16)}$. In previous trials, the increases in protein and decreases in carbohydrate have ranged from approximately $25-70 \mathrm{~g} / \mathrm{d}$ and benefits on systolic blood pressure have ranged from 1.4 to $5.9 \mathrm{mmHg}$, but a dose-response relationship is not clear $^{(8-11,29,30)}$. In the only previous trial to investigate the effects of animal protein specifically, as lean red meat, on blood pressure, a lower systolic blood pressure of $4 \mathrm{mmHg}$ was observed with protein (approximately $29 \mathrm{~g} / \mathrm{d}$ or $5 \%$ of energy) compared with carbohydrate control after 12 weeks of intervention. A limitation in interpreting the results of these intervention studies is that changes in blood pressure may be the result of changes in both protein and carbohydrate in the diet. In the present study, the increase in protein intake was $30 \mathrm{~g} / \mathrm{d}$ from the supplement, but was estimated to be approximately $20 \mathrm{~g} / \mathrm{d}$ from reported intake data. The mean systolic blood pressure difference over the 2 years was less than $1 \mathrm{mmHg}$. The results were similar for both the intention-to-treat and the per-protocol analyses.

Thus, available evidence suggests that partial substitution of carbohydrate in the diet with protein can improve blood pressure. However, these results have yet to be translated into effective and widely applicable approaches for the prevention and treatment of high blood pressure. A possible reason for this is that substantial substitution of carbohydrate with protein can be difficult to achieve and sustain in longterm dietary intervention studies. Few longer-term trials have been conducted, with the longest duration being 12 months ${ }^{(12,20)}$. The present trial is the first to investigate the longer-term effects over 2 years of increasing animal protein specifically, relative to carbohydrate, on blood pressure. In addition, our study did not involve energy restriction and weight loss. Our results provide data on the potential longterm impact of advice to increase protein intake. Although the trend observed at year 1 would be consistent with results of previous trials $^{(8-11,12,20,29,30)}$, there was no overall effect on blood pressure over the 2-year trial, and little difference between groups at year 2 .

There are several possible explanations for the lack of effect of protein, relative to carbohydrate, in the present study. The differences in protein and carbohydrate intakes were modest. Although advice to increase protein and reduce refined carbohydrate intakes is likely to result in modest increases in protein intake, perhaps in the order of $20-30 \mathrm{~g} / \mathrm{d}$, the magnitude of this change may not be enough to substantially alter blood pressure. Previous short-term trials have shown benefits on blood pressure with often larger differences in protein intake between groups ${ }^{(8-11)}$. The high prevalence of the use of antihypertensive medication and the change in medication use during the trial may also have masked effects on blood pressure. However, the similar estimates from the intentionto-treat and per-protocol analyses do not support this argument. In addition, although the high prevalence of the use of antihypertensive medication is a potential limitation of our study, this prevalence is similar to many other populations, and thus our results are applicable to these populations. Another possibility is that the protein supplement used (whey) could be less effective than other forms of protein. The short-term effects of whey protein on blood pressure have yet to be studied. A further possibility is that short-term effects are not sustained in the longer term. This may relate to diminished compliance with time, but our data from the per-protocol population suggest similar compliance at year 1 and year 2 .

An additional limitation of this study is the selection of women over 70 years as the study population. Previous studies to have investigated the effects of dietary protein relative to carbohydrate on blood pressure have recruited 
primarily men and women less than 70 years ${ }^{(8-12)}$. Both shortterm and longer-term effects of protein on blood pressure have not been previously investigated in an elderly population. Ageing is characterised by changes in the nervous and hormonal systems involved in the regulation of blood pressure $^{(31)}$. Therefore, conclusions based on the results of our study must take into account that older individuals compared to younger individuals may exhibit a different blood pressure response to an increase in protein intake. Furthermore, older men were not recruited to our study. Sex differences in regulation of blood pressure could also influence responsiveness to dietary changes ${ }^{(32)}$

In conclusion, we have shown that modest differences in protein intake, derived from whey, and carbohydrate intake, do not significantly influence blood pressure over 2 years. These results do not support the proposal that a higher whey protein intake in older women can have prolonged effects on blood pressures relative to carbohydrate intake. Additional prospective population studies and long-term randomised controlled trials are needed to investigate the potential long-term impact of higher protein intakes.

\section{Acknowledgements}

The present study is supported by the Australian National Health Medical Research Council (Project Grant: 458625) and the University of Western Australia Research Grants Scheme. We are grateful to Fonterra Brands Limited for providing whey protein isolate (Alacen 894) free of charge, and Anchor Foods, Fremantle, Western Australia for providing processing assistance for the test drink powder. We would like to thank Tricia Knox and Linda Gregory of the PathWest Laboratory at the Royal Perth Hospital, Western Australia for performing the biochemical analysis. None of the funding agencies had any role in the conduct of the study; collection, management, analysis or interpretation of the data; or preparation, review or approval of the manuscript. K. Z., D. K., V. S., A. D., C. W. B. and R. L. P. designed the research; K. Z., J. R. L., D. K., X. M., V. S., A. D., C. W. B. and R. L. P. conducted the research; J. M. H., K. Z. and R. J. W. analysed the data; J. M. H., K. Z., J. R. L. and R. L. P. wrote the paper; J. M. H. and K. Z. had primary responsibility for the final content. All authors read and approved the final manuscript. The authors declare that there is no conflict of interest.

\section{References}

1. Ezzati M, Lopez AD, Rodgers A, et al. (2002) Selected major risk factors and global and regional burden of disease. Lancet 360, 1347-1360.

2. Beilin LJ, Burke V, Cox KL, et al. (2001) Non pharmacologic therapy and lifestyle factors in hypertension. Blood Press $\mathbf{1 0}$, 352-365.

3. Appel LJ on behalf of the American Society of Hypertension Writing Group (2009) ASH position paper: dietary approaches to lower blood pressure. J Am Soc Hypertens 3, 21-31.

4. Altorf-van der Kuil W, Engberink MF, Brink EJ, et al. (2010) Dietary protein and blood pressure: a systematic review. PLoS One 5, e12102.
5. Appel LJ (2003) The effects of protein intake on blood pressure and cardiovascular disease. Curr Opin Lipidol 14, 55-59.

6. Lee YP, Puddey IB \& Hodgson JM (2008) Protein, fibre and blood pressure: potential benefit of legumes. Clin Exp Pharmacol Physiol 35, 473-476.

7. Elliott P (2003) Protein intake and blood pressure in cardiovascular disease. Proc Nutr Soc 62, 495-504.

8. Burke V, Hodgson JM, Beilin LJ, et al. (2001) Dietary protein and soluble fiber reduce ambulatory blood pressure in treated hypertensives. Hypertension 38, 821-826.

9. Appel LJ, Sacks FM, Carey VJ, et al. (2005) Effects of protein, monounsaturated fat, and carbohydrate intake on blood pressure and serum lipids: results of the OmniHeart randomized trial. JAMA 294, 2455-2464.

10. He J, Gu DF, Wu XG, et al. (2005) Effect of soybean protein on blood pressure: a randomized, controlled trial. Ann Intern Med 143, 1-9.

11. Hodgson JM, Burke V, Beilin LJ, et al. (2006) Partial substitution of carbohydrate intake with protein intake from lean red meat lowers blood pressure in hypertensive persons. Am J Clin Nutr 83, 780-787.

12. Delbridge EA, Prendergast LA, Pritchard JE, et al. (2009) One-year weight maintenance after significant weight loss in healthy overweight and obese subjects: does diet composition matter? Am J Clin Nutr 90, 1203-1214.

13. Prescott SL, Jenner DA, Beilin LJ, et al. (1988) A randomized controlled trial of the effect on blood pressure of dietary non-meat protein versus meat protein in normotensive omnivores. Clin Sci 74, 665-672.

14. Sacks FM \& Kass EH (1988) Low blood-pressure in vegetarians - effects of specific foods and nutrients. Am J Clin Nutr 48, 795-800.

15. Kestin M, Rouse IL, Correll RA, et al. (1989) Cardiovascular disease risk factors in free-living men: comparison of two prudent diets, one based on lactoovovegetarianism and the other allowing lean meat. Am J Clin Nutr 50, 280-287.

16. Wheeler ML, Fineberg SE, Fineberg NS, et al. (2002) Animal versus plant protein meals in individuals with type 2 diabetes and microalbuminuria: effects on renal, glycemic, and lipid parameters. Diabetes Care 25, 1277-1282.

17. Liu K, Ruth KJ, Flack JM, et al. (1996) Blood pressure in young blacks and whites: relevance of obesity and lifestyle factors in determining differences. The CARDIA Study. Coronary Artery Risk Development in Young Adults. Circulation 93, 60-66.

18. Stamler J, Liu K, Ruth KJ, et al. (2002) Eight-year blood pressure change in middle-aged men: relationship to multiple nutrients. Hypertension 39, 1000-1006.

19. Alonso A, Beunza JJ, Bes-Rastrollo M, et al. (2006) Vegetable protein and fiber from cereal are inversely associated with the risk of hypertension in a Spanish cohort. Arch Med Res 37, 778-786.

20. Gardner CD, Kiazand A, Alhassan S, et al. (2007) Comparison of the Atkins, Zone, Ornish, and LEARN diets for change in weight and related risk factors among overweight premenopausal women: the A TO Z Weight Loss Study: a randomized trial. JAMA 297, 969-977.

21. Friedewald WT, Levy RI \& Fredrickson DS (1972) Estimation of the concentration of low-density lipoprotein cholesterol in plasma, without use of the preparative ultracentrifuge. Clin Chem 18, 499-502.

22. Matthews DR, Hosker JP, Rudenski AS, et al. (1985) Homeostasis model assessment: insulin resistance and beta-cell function from fasting plasma glucose and insulin concentrations in man. Diabetologia 28, 412-419. 
23. Prince RL, Devine A, Dhaliwal SS, et al. (2006) Effects of calcium supplementation on clinical fracture and bone structure: results of a 5-year, double-blind, placebo-controlled trial in elderly women. Arch Intern Med 166, 869-875.

24. Britt H (1997) A new coding tool for computerised clinical systems in primary care-ICPC plus. Aust Fam Physician 26, S79-S82.

25. World Health Organisation (2009) Global Health Risks: Mortality and Burden of Disease Attributable to Selected Major Risks. Geneva: WHO. http://www.who.int/ healthinfo/global_burden_disease/GlobalHealthRisks_report_ full.pdf (accessed December 2010).

26. Kearney PM, Whelton M, Reynolds K, et al. (2005) Global burden of hypertension: analysis of worldwide data. Lancet 365, 217-223.

27. Burt VL, Whelton P, Roccella EJ, et al. (1995) Prevalence of hypertension in the US adult population: results from the
Third National Health and Nutrition Examination Survey, 1988-1991. Hypertension 25, 305-313.

28. Hajjar I \& Kotchen TA (2003) Trends in prevalence, awareness, treatment, and control of hypertension in the United States, 1988-2000. JAMA 290, 199-206.

29. Lee YP, Mori TA, Puddey IB, et al. (2009) The effects of lupin kernel flour-enriched bread on blood pressure: a controlled intervention study. Am J Clin Nutr 89, 766-782.

30. Belski R, Mori TA, Puddey IB, et al. (2010) Effects of lupinenriched foods on body composition and cardiovascular disease risk factors: a 12 month randomised controlled weight loss trial. Int J Obes 35, 810-819.

31. Benetos A, Salvi P \& Lacolley P (2011) Blood pressure regulation during the aging process: the end of the 'hypertension era'? J Hypertens 29, 646-652.

32. Reckelhoff JF (2001) Gender differences in the regulation of blood pressure. Hypertension 37, 1199-1208. 